\title{
RESENHAS
}

DOI: http://dx.doi.org/10.1590/So034-759020170611

\section{CADÊ MEU CELULAR? UMA ANÁLISE DA NOMOFOBIA NO AMBIENTE ORGANIZACIONAL}

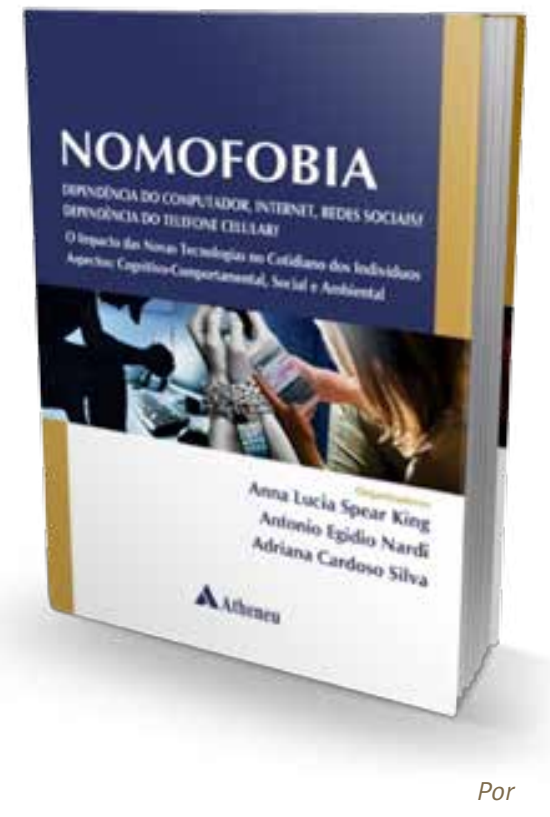

THYCIANE SANTOS OLIVEIRA

thycianest@hotmail.com Mestranda em Administração pela Universidade Potiguar, Programa de Pósgraduação em Administração - Natal - RN,

Brasil

LAÍS KARLA DA SILVA BARRETO laisbarreto@gmail.com Professora da Universidade Potiguar, Programa de Pós-graduação em Administração - Natal - RN, Brasil

WALID ABBAS EL-AOUAR walidbranco@gmail.com Professor da Universidade Potiguar, Programa de Pós-graduação em Administração - Natal - RN, Brasil

LIEDA AMARAL DE SOUZA lieda2009@gmail.com Professora da Universidade Potiguar, Escola de Gestão e Negócios - Natal - RN, Brasil

LEONARDO VICTOR DE SÁ PINHEIRO leonardopinheiro@hotmail.com Professor da Universidade Federal do Piauí Floriano - Pl, Brasil
NOMOFOBIA. Dependência do computador, internet, redes sociais? Dependência do telefone celular? 0 impacto das novas tecnologias no cotidiano dos indivíduos.

Anna Lucia Spear King, Antonio Egidio Nardi, \& Adriana Cardoso (Orgs.). São Paulo, SP: Atheneu, 2014. $327 p$.

É expressiva a mudança nos hábitos das pessoas com o surgimento e avanço da tecnologia móvel. Ao influenciar as relações individuais, sociais e de trabalho, essa mudança motivou o interesse dos pesquisadores reunidos neste livro em compreender as consequências associadas ao uso abusivo da tecnologia no âmbito clínico, cognitivo-comportamental, social e ambiental.

A obra Nomofobia mostra, de modo pioneiro no Brasil, a massificação e a utilização obsessiva de celulares e computadores pela sociedade, os impactos causados em cada indivíduo, bem como suas relações pessoais. Organizado por Anna Lucia Spear King, Antonio Egidio Nardi e Adriana Cardoso, o interesse na criação da obra surgiu devido às queixas e transtornos sociais observados em seus pacientes sobre o uso abusivo dos computadores e aparelhos celulares.

Com base no livro, o termo nomofobia tem origem na Inglaterra, sendo inspirado na expressão no-mobile, que significa "sem celular". Acrescenta-se, ainda, a palavra fobos, de origem grega, que significa fobia ou medo. Em outras palavras, nomofobia é, portanto, a angústia ou medo de o indivíduo ficar impossibilitado de se comunicar por meios virtuais. Ou seja, a fobia de estar sem o telefone celular, computador e/ou internet.

Tratada fundamentalmente nas áreas da Psicologia e Psiquiatria, a nomofobia pode se revelar também no ambiente organizacional, em razão das exigências de algumas empresas que obrigam a disponibilidade dos funcionários a todo o momento, onde quer que estejam. Nesse sentido, o tema passa a ser de fundamental relevância para as organizações, a fim de cuidar da saúde e bem-estar dos seus colaboradores.

A diferença entre os termos ansiedade, medo e fobia é estabelecida logo no início da obra: ansiedade é uma reação fisiológica do corpo que prepara para fugir ou lutar em uma situação de perigo, podendo provocar tremores, angústia, taquicardia e outros; o medo é definido como a interpretação de uma situação como perigosa para a pessoa, podendo ser acompanhado de ansiedade ou não; já a fobia está relacionada com um medo muito desproporcional, muitas vezes considerado irracional, que pode atrapalhar as atividades cotidianas e prejudicar a qualidade de vida.

Apesar dos grandes benefícios que as inovações tecnológicas proporcionaram para o mundo, cabe ressaltar que, no ambiente virtual, a realidade, às vezes, não é a real. Nesse contexto, o livro mostra os efeitos que a tecnologia está trazendo para os seres humanos, 
que agora se queixam de que a tecnologia os tem escravizado, mais do que ajudado. Com efeito, esses elementos começam a causar dependência às pessoas, que estão vendo suas vidas se restringirem muito pelo uso inadequado dessa tecnologia.

Os estudos envolvendo esse tema no Brasil ainda são escassos, o que leva a crer que este é um campo vasto de conhecimento a ser explorado no País. Atualmente, as principais pesquisas na área acontecem no Laboratório de Pânico e Respiração (LABPR), localizado no Instituto de Psiquiatria (IPUB) da Universidade Federal do Rio de Janeiro (UFRJ), onde são observadas as mudanças cognitivas, comportamentais, sociais e familiares dos pacientes que lá são atendidos.

Em 2008, a equipe do LABPR identificou alterações no comportamento dos pacientes com transtornos de ansiedade relacionados ao uso indevido do computador e dos smartphones, interferindo de modo considerável na qualidade de vida dos usuários. Essa constatação motivou a equipe a desenvolver estudos científicos que pudessem embasar essa descoberta, que, por se tratar de um assunto recente no Brasil, necessita de pesquisas pareadas e initerruptas a fim de que sejam acompanhadas as inteferências e mudanças na vida das pessoas de modo geral.

O livro é composto por 29 capítulos que abordam e relacionam a nomofobia com os vários tipos de transtornos que uma pessoa pode desenvolver, tais como: ansiedade, pânico, impulso, fobia social, transtorno obssessivo-compulsivo, dependência patológica, entre outros. Formado pela junção de artigos de diversos autores, a obra também apresenta implicações para a saúde mental, comportamento sexual, aspectos econômicos e os impactos ambientais ocasionados pela quantidade elevada de equipamentos eletroeletrônicos descartados.

A dependência patológica do uso do aparelho celular, de acordo com os pesquisadores, pode ser comparada ao comportamento de uma pessoa viciada em drogas, causando uma conduta compulsiva e perda de controle. É importante ressaltar que o problema não é, necessariamente, da tecnologia em si, mas da utilização que se faz a partir dela. Da timidez, podese desencadear uma fobia social. E a ansiedade de não controlar uma inquietação por estar sem o telefone pode causar sintomas físicos negativos, interferindo no desempenho de uma pessoa.

Levando-se em consideração o ambiente organizacional, algumas empresas incorporaram em suas atividades diárias o uso do telefone celular, tendo em vista os benefícios que podem ser proporcionados, os quais incluem: a facilidade de acesso à internet, e-mails e maior rapidez na comunicação. Em contrapartida, apesar das inúmeras vantagens dessa tecnologia, existem prejuízos decorrentes da sua má utilização, como problemas ergonômicos e a diminuição da concentração nas atividades de trabalho.

Alguns profissionais tornam-se "escravos do trabalho" em função de estarem permanentemente on-line, como se estivessem sempre de plantão, fazendo hora extra com 0 telefone celular ligado. Muitas empresas se utilizam dessa ferramenta e a oferecem como benefício ao funcionário, comparando-o ao plano de saúde ou vale-alimentação. Nas mais diversas profissões, a rotina de trabalho está associada ao uso contínuo do celular, como no caso de empresários, executivos, vendedores, profissionais do Marketing, professores, médicos, psicólogos e outros.

Apesar de facilitar a comunicação organizacional e profissional, o uso excessivo do celular pode colaborar para o desenvolvimento de um padrão workaholic, influenciando a forma como o indivíduo trabalha, se relaciona e vive. De acordo com o livro, há evidências de que a sobrecarga de trabalho em indivíduos que utilizam o telefone celular como meio de comunicação com clientes e empresa gera comportamentos mais compulsivos e competitivos no local de trabalho.

Qualquer pessoa está sujeita à nomofobia. Assim como os jovens que nasceram no mundo tecnológico, os funcionários de empresas que precisam estar conectados e disponíveis 24 horas por dia também podem ser afetados. Aos poucos, a nomofobia faz com que as pessoas se distanciem e se isolem da convivência com a família e amigos, para ficar no mundo virtual, causando mudanças drásticas nessas relações. É um contexto paradoxal, pois, ao mesmo tempo que não há uma relação pessoal, existe um contato no mundo virtual com outros indivíduos, aproximando os que estão longe e, muitas vezes, afastando os que estão perto.

Em síntese, o livro conseguiu reunir diversas temáticas relacionadas ao assunto, contribuindo de maneira crítica para a compreensão dos fenômenos da dependência tecnológica, que envolve aspectos do comportamento humano nos mais variados contextos de investigação. A partir da obra, é possível verificar que o interesse por estudos sobre as consequências do uso das mídias digitais nas pessoas é relativamente recente, constituindo-se num campo multi, inter e transdisciplinar, que desafia os pesquisadores a compreenderem sua complexidade a partir de um enfoque múltiplo. Nesse sentido, é necessária uma maior investigação das suas implicações no âmbito organizacional, uma vez que a dependência à rede pode ocorrer não só por prazer social, mas também por obrigações relacionadas ao trabalho. A utilização da tecnologia deve ser exercida, portanto, com cautela, sob pena de converter-se em motivo para a completa anulação de seus benefícios. Da vida real à virtual, afinal, onde vamos parar? 